\title{
Editorials
}

\section{Antibiotic overuse:}

\section{a key driver of antimicrobial resistance}

The widespread use of antibiotics is estimated to have extended average life expectancy by two decades, shifting the paradigm from communicable to noncommunicable diseases. Antimicrobials and antibiotics in particular have paved the way for major advances in cancer treatment, organ transplantation, and surgery, irrevocably changing the scope of modern medicine.

Every time a new antimicrobial is introduced, drug resistance to that antimicrobial follows, sometimes swiftly, and this occurs for antibiotics, antivirals, and antifungal therapies. Antimicrobial treatment places selective pressure on the organism, favouring the emergence of drug-resistant strains. This is not a new problem: antibiotic resistance emerged within a decade of the first clinical trials of penicillin, with more than $50 \%$ resistance among Staphylococcus aureus by the end of the 1940s. Until recently we have escaped the dire consequences of antimicrobial resistance because there has been a stream of new antibiotics. However, over the past 20 years the number of pharmaceutical companies investing in this area has dwindled from 18 to 4, inevitably leading to stalled drug development.

Antimicrobial resistance affects every country because infections do not respect international boundaries or borders. Each time a person travels they take their active infections and colonising bacteria with them, spreading drug-resistant organisms across the globe. Many countries overuse antibiotics, particularly in hospitals. Although hospital prescribing accounts for only $20 \%$ of human usage, it is important because it is concentrated, and because hospitals are fertile breeding grounds for drug-resistant bacteria. In animals and fish antibiotics are used as a substitute for good hygiene, with little understanding of how this might impact on antimicrobial resistance in humans. As a society we must urgently reconsider how we use antimicrobials to preserve this valuable resource for future generations.

\section{ANTIBIOTIC USE IN PRIMARY CARE}

An estimated $80-90 \%$ of antibiotics are prescribed for oral use in primary care. ${ }^{1}$ Half of these prescriptions are for respiratory tract infections and one-sixth are prescribed for urinary tract infections.
Professional guidance endorsed by the Royal College of General Practitioners (RCGP) recommends which antibiotics to prescribe in primary care and when they are indicated. ${ }^{2}$ Antibiotics are not recommended for patients with coughs, colds, and viral sore throats. However, in a recent survey of antibiotic prescribing in UK general practice, half of all patients consulting for these conditions were prescribed an antibiotic. ${ }^{3}$ Many GPs prescribe for minor infections such as sore throat or otitis media because of concerns over the risk of suppurative complications such as quinsy or mastoiditis. Such concerns are not borne out by the data: hundreds of patients require antibiotic treatment to prevent one adverse event. ${ }^{4}$ Further there is little evidence that antibiotic treatment has a significant impact on the duration or severity of symptoms. ${ }^{5}$

Across the UK there is marked variation in antibiotic prescribing with some practices prescribing at double the rate of lowprescribing practices

(Figure 1). For example, whereas $8.4 \%$ of patients registered with a GP in Newcastle West received an antibiotic prescription in 2012, only $4 \%$ were prescribed an antibiotic in Camden in North London, against a national average of $6.4 \%$. This heterogeneity in prescribing is echoed by data from the European Centre for Disease Prevention and Control (ECDC), with marked variation in antimicrobial consumption at national level across Europe. ${ }^{6}$ In 2011 antibiotic consumption in the UK was slightly lower than the European Union average at 18.8 defined daily doses (DDD) per
1000 habitants per year versus 19.5 DDD for the EU. Greece had the highest rates of antimicrobial consumption (35.1 DDD per 1000 inhabitants) with the Netherlands reporting the lowest rates $(11.4 \mathrm{DDD}$ per 1000 inhabitants). Notwithstanding the inherent difficulties in comparing data drawn from different countries, this variation suggests there is major scope for safely reducing antimicrobial use, both in the UK and across Europe.

\section{REDUCING ANTIMICROBIAL USE IN PRIMARY CARE}

The decision to prescribe an antibiotic is complex, based not only on an assessment of the likely risk of complications, but also on the doctor-patient relationship, the patient's psychosocial history, and the time constraints of the consultation. A number of approaches have been evaluated with the aim of reducing consultations and prescribing for minor infections. These mainly focus on either reducing diagnostic

Figure 1. Proportion of registered patients in each clinical commissioning group who received an antibiotic in 2012. Image provided by James Ambler of Moor Consulting using NHS data provided by the Health and Social Care Information Centre.

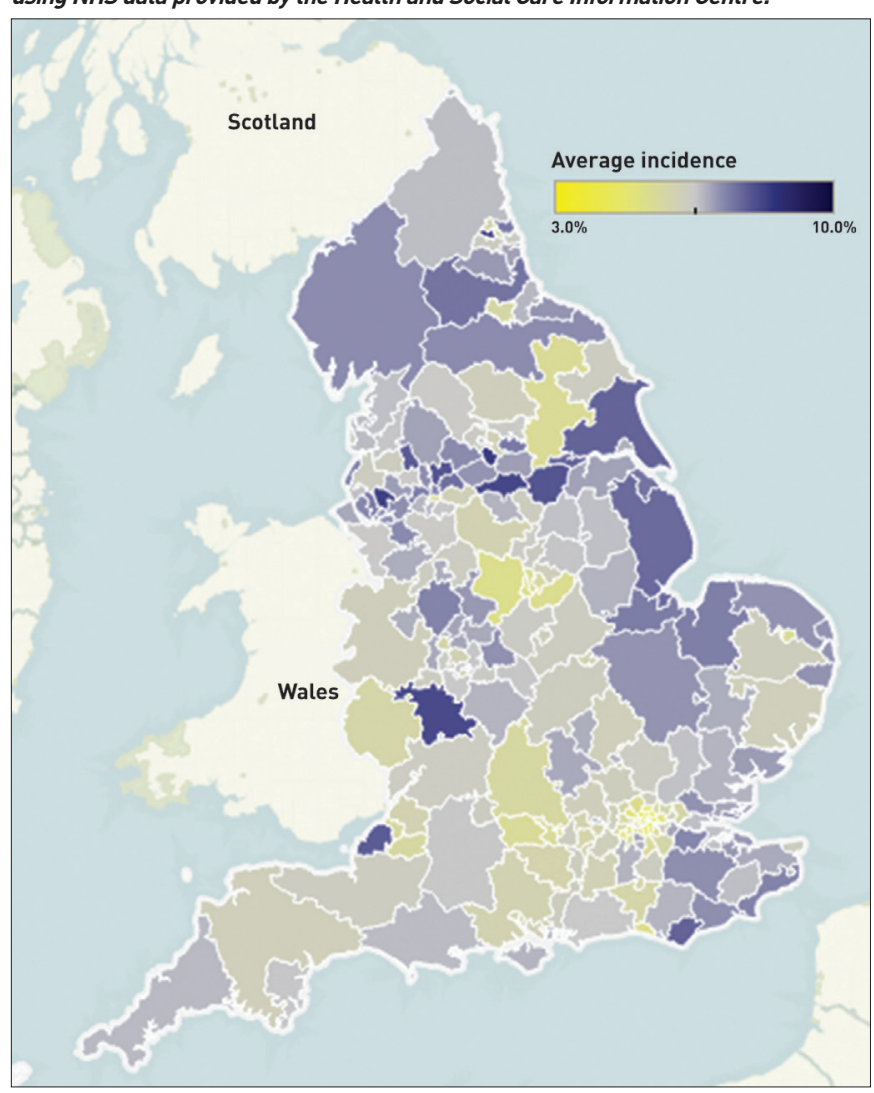




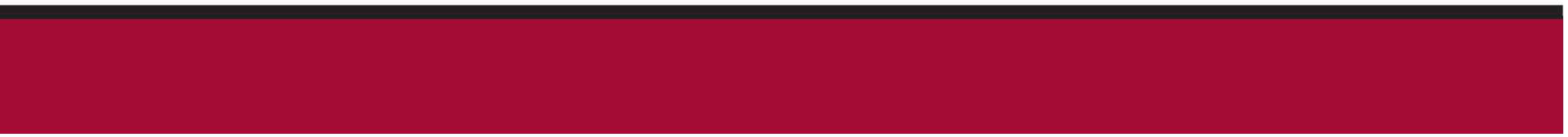

\section{"Across the UK there is marked variation in antibiotic prescribing ...}

uncertainty or altering physician and patient behaviour. In a multicentre trial in six European countries, point-of-care testing using $\mathrm{C}$-reactive protein (CRP) or communication training led to a marked reduction in antibiotic prescribing for acute respiratory tract infection in primary care. ${ }^{7}$ However, the greatest effect was seen by combining these interventions, which led to a $62 \%$ reduction in antibiotic prescriptions. Scoring systems such as the Centor criteria and latterly the FeverPAIN score have been used to try to target antibiotic treatment, but they are poorly predictive of bacterial infection and outcome. ${ }^{8}$ Delayed prescribing has been shown to reduce antibiotic use by patients without negatively impacting on patient outcome and has the added benefit that patients become less reliant on antibiotics. ${ }^{9}$ Given the major variation in antibiotic prescribing in primary care, there is real scope to evaluate how we could use these and other interventions most cost-effectively across the NHS to reduce inappropriate antibiotic prescribing. The Treat Antibiotics Responsibly, Guidance, Education, Tools (TARGET) antibiotic toolkit has been developed to support this aim in primary care..$^{10}$ It is envisaged for use by the whole primary care team as a short workshop and includes information and tools such as posters and videos for patients and clinicians. Its aim is to reduce inappropriate prescribing, change social norms around prescribing, and influence attitudes towards antibiotic resistance and use.

\section{FUTURE STEPS}

Reducing inappropriate antibiotic use in primary and secondary care is only one part of the solution. The antibiotics we have must be conserved while we reinvigorate research into new rapid diagnostics and innovative antimicrobials. Effective hygiene and infection control must also be prioritised. We must work effectively across human and animal health sectors, recognising that human health is connected to the health of animals and the environment. This includes working with all health professionals, their regulatory agencies, and their enforcement arms. This is known as the 'One Health' approach and it is at the core of the UK government's strategy on antimicrobial resistance. ${ }^{11}$

The problems of antimicrobial resistance will only be solved through global cooperation and mutual support from governments across the world working through the relevant United Nations organisations, the World Health Organization, the Food and Agriculture Organization, and the inter-governmental World Organisation for Animal Health (OIE). Great steps have been taken, for example, through the recent adoption of a resolution on antimicrobial resistance at the World Health Assembly and the subsequent global action plan, but we need to do more. We must find innovative ways to reduce antimicrobial prescribing in primary care and in our hospitals. Each of us can practise good hygiene and only take antibiotics when really necessary, and we should encourage patients to safely selfmanage minor infections, reducing reliance on antimicrobials. As a society we need to recognise that antibiotics are fundamental to how we practise modern medicine. We must value them accordingly.

\section{Laura J Shallcross,}

Clinical Lecturer in Public Health, Research Department of Infection and Population Health, University College London, London, and Office of the Chief Medical Officer for England, Department of Health, London, UK.

\section{Dame Sally C Davies,}

Chief Medical Officer for England, Office of the Chief Medical Officer for England, Department of Health, London, UK.

\section{Provenance}

Freely submitted; not externally peer reviewed.

DOI: 10.3399/bjgp14X682561

\section{ADDRESS FOR CORRESPONDENCE}

\section{Laura J Shallcross}

Research Department of Infection and Population Health, University College London, Farr Institute of Health Informatics Research, 222 Euston Road, London NW1 2DA, UK

\section{E-mail: l.shallcrossđucl.ac.uk}

\section{REFERENCES}

1. Goossens H, Ferech M, Vander SR, et al. Outpatient antibiotic use in Europe and association with resistance: a cross-national database study. Lancet 2005; 365(9459): 579 587.

2. Public Health England. Management of infection guidance for primary care for consultation and local adaptation. https://unw. gov.uk/government/uploads/system/uploads/ attachment data/file/362394/PHE Primary Care_guidance_09_10_14.pdf laccessed 3 Nov 2014).

3. Hawker JI, Smith S, Smith GE, et al. Trends in antibiotic prescribing in primary care for clinical syndromes subject to national recommendations to reduce antibiotic resistance, UK 1995-2011: analysis of a large database of primary care consultations. J Antimicrob Chemother 2014: pii: dku291. [EPub ahead of print].

4. Petersen I, Johnson AM, Islam A, et al. Protective effect of antibiotics against serious complications of common respiratory tract infections: retrospective cohort study with the UK General Practice Research Database. BMJ 2007; 335(7627): 982.

5. Little P, Hobbs FD, Moore M, et al. Clinical score and rapid antigen detection test to guide antibiotic use for sore throats: randomised controlled trial of PRISM (primary care streptococcal management). BMJ 2013; 347: f5806; DOI: 10.1136/bmj.f5806.

6. European Centre for Disease Prevention and Control. Surveillance of antimicrobial consumption in Europe 2011. http://www.ecdc. europa.eu/en/activities/surveillance/ESAC-Net/ Pages/index.aspx (accessed 3 Nov 2014).

7. Little P, Stuart B, Francis N, et al. Effects of internet-based training on antibiotic prescribing rates for acute respiratory-tract infections: a multinational, cluster, randomised, factorial, controlled trial. Lancet 2013; 382(9899): 11751182.

8. Little P. Stuart B, Hobbs FD, et al. Predictors of suppurative complications for acute sore throat in primary care: prospective clinical cohort study. BMJ 2013; 347: f6867; DOI: 10.1136/bmj. f6867.

9. Little P, Moore M, Kelly J, et al. Delayed antibiotic prescribing strategies for respiratory tract infections in primary care: pragmatic, factorial, randomised controlled trial. BMJ 2014; 347: f6867; DOI: 10.1136/bmj.f6867.

10. Royal College of General Practitioners. TARGET antibiotics toolkit. http://www.rcgp.org.uk/ clinical-and-research/target-antibiotics-toolkit. aspx (accessed 3 Nov 2014).

11. Department of Health. UK five year antimicrobial resistance strategy 2013 to 2018. https://www. gov.uk/government/publications/uk-5-yearantimicrobial-resistance-strategy-2013-to-2018 (accessed 3 Nov 2014). 